but the influence on the properties of the material as a whole of the symmetrically disposed, recurring benzene nuclei in the linear chain could not be predicted with any degree of certainty. All that could be inferred. was that, in comparison with the purely aliphatic fibre-forming polymers, the chains would be less flexible, since there are fewer points of rotation in a given length. Nevertheless, they apparently retain sufficient suppleness to permit cold-drawing. That the poly-ester would have a high melting point appeared probable but by no means certain.

The possible effect of the ester linkages on the general chemical stability of the fibres was a very speculative matter. On one hand, unlike the amide linkages in the poly-amides (and in natural silk) the ester linkage should not induce instability to heat and light, and it has now been reported that 'Terylene' is notably resistant towards these agencies. On the other hand, the normal susceptibility of the ester linkage to hydrolysis at first gave rise to some misgivings. It was therefore rather surprising to find that 'Terylene' fibres remained apparently unaffected when subjected to quite severe hydrolytic treatments. This behaviour must be accounted for by the high degree of orientation and the close molecular packing - the density of 'Terylene' approximates to $\mathbf{1 \cdot 4}$ whereby access of hydrolytic agents is rendered difficult, if not altogether prevented. In this connexion it is of interest to remark that undrawn 'Terylene' fibres are readily dyed by many dyestuffs commonly used for the dyeing of cellulose acetate rayon, but after cold-drawing the dye affinity of the fibres is very much reduced.

The higher polymeric polymethylene terephthalates show diminishing melting points with increasing length of the polymethylene chain separating the ester linkages; trimethylene terephthalate melted at $221^{\circ} \mathrm{C}$. and the decamethylene ester at $123^{\circ} \mathrm{C}$. These higher esters, however, all yielded orientated fibres when in a condition of sufficiently high molecular weight. On the other hand, esterification of diethylene glycol with terephthalic acid gave only amorphous, rubber-like poly-esters from which useful fibres could not be obtained. It is known that similar products result from the esterification of diethylene glycol and its homologues with the acids $\mathrm{HOOC}\left(\mathrm{CH}_{2}\right)_{n} \mathrm{COOH}$. The effect of the ether linkage is, however, variable. The higher polymers of ethylene oxide are crystalline, and Dr. J. T. Dickson, while engaged on the present studies, obtained microcrystalline fibre-forming polymers by esterifying the glycols $\mathrm{HO}\left(\mathrm{CH}_{2}\right)_{n} \mathrm{OH}$ with the acid

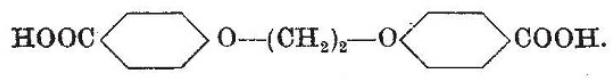

From acids of the series $p$-HOOC- $-\mathrm{C}_{6} \mathrm{H}_{4}\left(\mathrm{CH}_{2}\right)_{n}$ $\mathrm{OH}$, microcrystalline fibre-forming poly-esters were obtained by self-condensation. These are of the type :

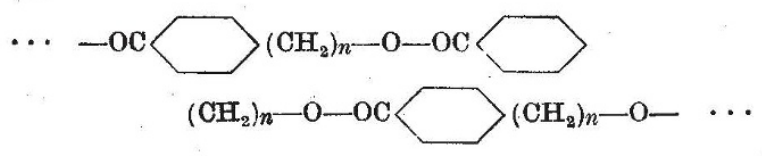

The poly-ester derived from $p$-hydroxymethyl benzoic acid is in many respects not dissimilar from 'Terylene', but shows a greater tendency to persist in the amorphous condition-behaviour perhaps attributable to its rather lower degree of molecular symmetry.

The investigations which have now been briefly outlined were pursued by my colleagues (in particular; Dr. J. T. Dickson, Mr. W. K. Birtwistle and Dr. G. G. Ritehie) and $m e$ in the laboratories of the Calico Printers' Association, Ltd., during the period 1939-41, and met with many difficulties on account of the War. The preparation of 'Terylene' on a somewhat larger scale ultimately became necessary, and this was undertaken at a later period by Dr. D. V. N. Hardy of the Chemical Research Laboratory (Department of Scientific and Industrial Research), at the request of the Ministry of Supply. A sample of 'Terylene' prepared by Dr. Hardy was eventually submitted to Imperial Chemical Industries, Ltd., for preliminary evaluation.

I would like to conclude, this short account by an acknowledgment of my indebtedness first to the work of Carothers, of which the present investigations are a logical extension; secondly; to my early association with the late C. F. Cross, the discoverer of the viscose reaction, from whom I first acquired an interest in the chemistry and structure of fibres that has endured for many years.

"See "Part 1 of the collected papers of W. H. Carothers in Vol. 1 of "High Polymers" (Interscience Publishers, Inc., New York, 1940). 2 For a more detailed discussion of this question see Whinfield, Chem. and Ind., 62, 354 (1943).

${ }^{3}$ J. Amer. Chem. Soc., 31, 1919 (1909).

$$
15 / 2
$$

\section{GEOPHYSICAL PROSPECTING AND ENGLISH OILFIELDS}

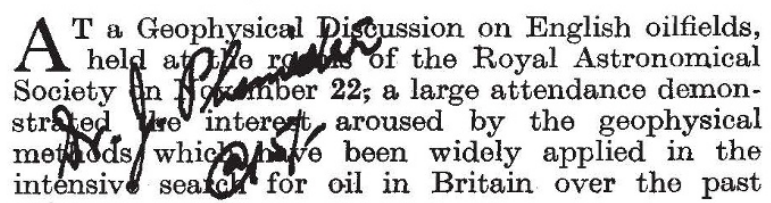
ten years.

Dr. J. Phemister, in opening the discussion, gave a general account of the types of structure in which oil may be found, of the distribution of such structures in England, and of the geophysical methods employed in their detection. The types of structure possible in England include the stratigraphic trap, the closed anticline or dome, and the traps against an unconformity or a fault. In each case the porous stratum which is a potential oil reservoir must be sealed off by impermeable rock against both vertical and lateral dissipation of fluid, and the seal must have remained effective. In considering the distribution of structures which might act as oil-traps, the field of inquiry may be limited to those geological formations which provide some indication of the presence of oil. Such indications include seepages, gas-escapes, oil-impregnations, elaterite veins, and bituminous coatings in fractures and joints. The formations suggested by such signs as worthy of consideration are the Wealden and Corallian of the south of England, the Coal Measures, Millstone Grit and Carboniferous Limestone of the Midlands, and in Scotland the Calciferous Sandstone Series. From a well at Hardstoft in the Carboniferous Limestone, more than 3,600 tons of oil had been obtained in the years 1919-38. To these possibilities the Magnesian Limestone of northern Yorkshire has recently been added, 
as a considerable gas-field in it has been proved by boring.

Closed anticlines in the Corallian and Wealden of southern England have now been extensively tested but no oil-field has been found. The main purpose of geophysical survey in this region would be to locate structural crests in Mesozoic strata below a cover of Tertiaries, and to determine the depths to the Palæozoic platform against which the Mesozoic strata overlap unconformably.

Structures in Carboniferous strata west of the Pennine Chain have so far proved non-productive, but east of this line four small oil-fields have since 1939 produced more than 300,000 tons of oil. They occur in closed anticlines in Millstone Grit which are concealed from surface observation by a thick unconformable cover of Jurassic, Triassic and Permian sediments. The structures were located principally by seismic survey, and this discovery represents a great achievement in the application of quantitative methods of refraction surveying on the part of the geophysical staff of the Anglo-Iranian Oil Co. In the search for similar oil-bearing structures, geophysical surveys have been extended over wide areas of Lincolnshire, Nottinghamshire and Norfolk. Many structures have been found, which although they have not been productive, are thought to indicate possibilities which should not be neglected.

In prospecting for concealed structures of the kind in question, two classes of geophysical survey-the gravitational and the seismic-are of particular value. Gravitational survey may be carried out by the Eötvös balance or by the gravity meter (gravimeter). The latter, being more rapid in operation and requiring less laborious corrections, is more suited to reconnaissance survey and has been extensively used in England by the oil companies. This instrument measures the amount by which $g$ changes between a base station and other stations distributed over the area to be surveyed. Corrections for latitude, altitude and, when necessary, terrain are applied, and from the corrected observations a chart showing contours of equal difference in $g$ (isogams) is prepared. The isogam chart shows the positions of local gravity maxima. These may be rendered less apparent but cannot be obliterated by regional changes.

Interpretation of gravitational surveys is based on the fact of experience that, close above the crest of a dome formed in a normal series of sediments, the force of gravity reaches a local maximum value. Similarly, above the position where an unconformable platform of old rocks comes nearest to the surface, gravity attains a maximum. Between these two structures, fundamentally different geologically, gravitational survey may not be able to discriminate, but it will supply the information necessary to decide the position for a boring which will prove the nature of the rocks in the concealed structure at least expense.

Seismic surveys also may be carried out by two methods. In the reflexion methods, depth to a bed which is accepted as an areal marker is deduced from the time elapsing between the firing of a shot at the surface and the arrival of the wave reflected from the bed. The method has not proved reliable in investigating the presence and depth of the Carboniferous Limestone in England. The refraction method, on the contrary, has proved capable of contouring the top of this formation with considerable precision, and its predictions have been checked by boring. Refraction survey may be carried out by the procedure of arc-shooting in which the seismographs are stationed on the are of a circle of about two to three miles radius and centred on the shotpoint. Anomalously short travel-time signifies the approach towards the surface, along the radius concerned, of a high-velocity medium. By shooting a number of arcs, the interesting area can be delimited. In straight-line shooting the seismographs are set out on a line through the shot-point, and the time-distance graphs constructed from the observations yield data for calculating the depth to the refracting interface and the average velocity of the waves in the overlying and underlying rocks. The velocity is to a considerable degree diagnostic of the rocks, as the following figures, provided by Mr. R. Davies, chief geophysicist, Anglo-Iranian Oil Co., show : Keuper Marl, 7,600-9,000 ft. per sec.; Coal Measures strata, 12,000-14,000 ft. per sec.; Carboniferous Limestone, 18,500-19,500 ft. per sec.

A gravitational survey at present in progress in the region between Bristol and London, and the results achieved up to date, were then described. by Mr. L. H. Tarrant, of the geophysical staff of the Anglo-Iranian Oil Co., Ltd. The instrument in use is the Frost gravity meter, which consists of an air. damped box-beam carrying at one end a gold weight and at the other a drum to compensate air-buoyancy. A frictionless pivot is effected by a ligature device. The beam is suspended by a mainspring which is attached to the framework vertically above the axis of rotation of the beam and is in an almost astatized condition. By raising or lowering the point of attach. ment of the mainspring, the beam is set for the average value of gravity of the region which is to be surveyed. Observations are made by reading on a divided dial the rotation required to increase or decrease the tension on a reading spring required to return the beam to the null position corresponding to an arbitrary zero of gravity anomaly at a station accepted as the base station of the survey. The divisions of the dial are calibrated by reading at stations between which there is a known difference of gravity. An instrumental correction must be applied to the observations for drift of the zero ; this is determined empirically by re-occupying an earlier station at two-hour intervals, and applied on the assumption of a linear change with tirne. T'emperature correction is eliminated by thermostatic control of the instrument. The sensitivity of this gravity meter is rather better than $1 / 50$ milligal $(0 \cdot 000,02$ $\mathrm{cm}$. $/ \mathrm{sec}^{2}$ ), and the probable error of an observation estimated from a number of observations at individual stations is $1 / 30$ milligal.

The area which it is intended to survey covers about 5,000 square miles and overlaps in the south-west the locus of a gravity meter survey south of the Mendip Hills carried out earlier by the Gulf Exploration Co., Ltd. About 2,000 square miles have been covered and nearly four thousand stations occupied. A magnetic survey has been run concurrently but not with such detail, 850 observations having been made. The chart of isogams constructed from the observations corrected for difference in latitade, elevation and, in some cases, terrain, reveals a regular disposition of maximal and minimal areas of gravity anomaly. On the west, high values of gravity are conspicuous and are readily correlated with the Mendip anticline and the partly concealed outcrop of the Carboniferous Limestone along the eastern flank of the Bristol basin. The Mendip axis can be traced under cover of the Mesozoic strata as a long 
spur of diminishing gravity anomaly, and low maximal ridges indicate its continuation as a line of minor importance which curves east and then eastsouth-east beneath the north margin of Salisbury Plain.

The most remarkable and unexpected feature of the isogam chart is a deep trough of low-gravity values extending in a south-north direction approximately through Cirencester. From this axis gravity increases steadily and rapidly eastwards, and the chart shows a plateau of high gravity with two broad maximal areas between Oxford and Swindon and north-west of Oxford. Magnetic anomalies show a similar areal disposition of high and low values, but the maxima are considerably displaced from the gravity 'highs'. No geological interpretation of these significant gravity anomalies is being put forward at present by the Company's scientific workers, who hope to obtain complementary data by the application of seismic refraction methods of survey. It is, however, of interest and importance to recall that a boring at Burford reached Coal Measures at 1,200 ft. from surface. The difference found by the gravity meter between the values of $g$ at Bristol and Oxford is 8.5 milligals, the difference by pendulum measurement being 10 milligals.

The rate of survey by gravity meter is high in a country so well provided as England with good roads and with bench-marks, spot-levels and contours. The instrument can then be transported rapidly from station to station in a motor-car, and little time need be spent in surveying station sites for exact position and elevation. The average area covered each day in the survey described by Mr. Tarrant was 10 square miles, and the average number of stations occupied was nineteen. In countries poorly provided with topographic maps progress is very much slower; and where the ground conditions are difficult, it is estimated that to keep the gravity meter fully employed the services of three topographic surveyors are required.' The instrument itself is easily portable, being of small bulk, moderate weight (35 lb.) and possessing a reliable system of clamps.

Mr. Tarrant was followed by Mr. J. E. R. Wood, also of the Anglo-Iranian geophysical staff, who described, in illustration of seismic refraction survey, an investigation which has just been carried out in north-east Yorkshire. The object of the survey was to study the Magnesian Limestone, which was already known to occur at $2,400 \mathrm{ft}$. in a boring one mile south of Redcar. To obtain basic information, the seismic survey was begun by carrying out a line-shoot as near as possible to this boring and orientated parallel to the probable underground strike of the limestone. It was found that the limestone acted as a refracting medium transmitting waves with a velocity of $19,500 \mathrm{ft}$. per sec. and that the average velocity in the overlying strata was $11,800 \mathrm{ft}$. per sec. From inspection of the time-distance graph and the amplitudes of the pulses, which were becoming weak at $15,000 \mathrm{ft}$., it was decided that the main survey by arc-shooting would be most effectively carried out using a radius of $14,000 \mathrm{ft}$. A system of arcs was then laid out, and in order to avoid distortion of the arc-time profile the shot-points were located suitably to the inclination of the refracting medium, so far as this may be indicated by the contours of the base of the Rhætic series.

From the results of arc-shooting, time-contours of interval $1 / 100$ sec. were constructed over the area from the sea to Upleatham Hills in the south and between Marske and Grangetown. The contours revealed a dome in the Magnesian Limestone below the southern outskirts of Redcar, and a bore has since been drilled. The difference in depth of the limestone in the two borings differed from that calculated from the seismic results by only $40 \mathrm{ft}$., a length representing $3 / 1000$ sec. It is of interest to note that the system of arcs and lines shot over the area contained three closed polygons, around which the sum of the time differences was small and less than the limit of accuracy of measurement. This fact indicates that the pulses employed came from the same stratum throughout the survey, and that there are no significant changes of velocity in either the refracting medium or the overlying strata. In extending the survey southwards, difficulties in interpreting the results were encountered, and are ascribed to $(a)$ distortion of arc-time profiles when shot across troughs and, possibly, faults in the limestone; (b) the possibility of change in the true velocity in the refracting stratum; and (c) the possibility that the pulses did not arrive from the same bed on reversal of the direction of shooting.

In opening the general discussion which followed the formal contributions, Prof. V. C. Illing stressed the distinction between finding structure and finding oil. Suitable structure is necessary, but of as great importance to the main issue is the geological history of the strata in which oil is sought; and in assessing the oil-bearing potentialities of a region, as great consideration must be devoted to this aspect of the problem as to the discovery of structure. While there can be no question that certain British rocks had contained oil, is it to be expected in the light of their past geological history of severe folding and rupture that they now retain sufficient to repay the expense of intensive search ? Prof. Illing said he had some years ago expressed his dubiety, and he continued to be dubious of an affirmative answer to this question. Regarding the purely geophysical aspect of the search for oil, one marvelled at the precision of predictions based on the results of seismic refraction survey. He was puzzled, however, by the failure of the reflexion method to yield reliable evidence of the Carboniferous Limestone, and would be greatly interasted to know what explanation might be adduced.

The production of considerably more than 300,000 tons of crude oil which has already been attained was mentioned by Prof. A. O. Rankine, who emphasized the importance of the part played by geophysical survey in this achievement. While the evidence from borings and mining for coal had indicated the possibility of a fold near Eakring, it was by geophysical survey by the seismic refraction method that the existence of a closed structure in the Carboniferous Limestone had definitely been proved. $\mathrm{He}$ left it to $\mathrm{Mr}$. Wyrobek to discuss the failure of the reflexion method. Referring to the interesting nature of the gravitational anomalies between Bristol and Oxford, he hoped that it would be possible for the geophysicists of the Anglo-Iranian Oil Company to investigate by seismic refraction tests the buried structures which had been indicated by the gravity meter surveys. Mr. Wyrobek then put forward his view that reflexion of compressional waves is most efficiently effected when the high-velocity medium is comparatively thin and is, so to speak, suspended in low-velocity strata. He believed the lack of success in detecting the Carboniferous Limestone by seismic 
reflexion survey was due to the massive character of the limestone, which absorbed a high proportion of the energy. He pointed out also that it is covered by strata of Millstone Grit and Coal Measures age, which have fairly high velocity characteristics. In contrast to this purely physical explanation, the suggestion was made by Prof. W. G. Fearnsides and supported by Prof. O. T. Jones that the existence of a transition zone of interbedded limestones and shales between the Millstone Grit strata and the massive limestone may be responsible for the confusing and baffling reflexions.

In reply to a question by Mr. Wyrobek whether the accuracy of prediction of depth of the Magnesian Limestone from refraction shooting had been tested in the Redcar area, Mr. Wood said that the discrepancy between prediction and boring data was $50 \mathrm{ft}$. at $2,120 \mathrm{ft}$. depth.

Dr. E. C. Bullard, in elosing the discussion, directed attention to the fundamental advances which are being achieved alike in the study of the concealed geological structure of England and of the correlated magnetic and gravitational anomalies, and in the development of precise instruments of physical research, as a consequence of the quest for oil. The honours in the contribution of data fundamental to the elucidation of structure in England were evenly divided between the American and British oil companies. He would himself be interested to know whether Kater's pendulum station at Arbury Hill had been occupied in the gravity meter survey in the Oxford district, and Mr. Tarrant stated in reply that while this station lay considerably beyond his survey, the desirability that the gravity meter survey should be linked with absolute measurements of gravity was being constantly borne in mind by his Company's geophysical staff.

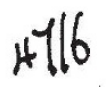

\section{SYNCARIDA IN RELATION TO THE INTERSTITIAL HABITAT}

\section{By DR. A. G. NICHOLLS \\ Department of Biology, University of Western Australia}

$\mathrm{T}$ HE Syncarida occupy an important position among the Crustacea, and are of considerable interest to carcinologists by virtue of certain primitive features which they show. The more typical forms, Anaspides and Paranaspides, are familiar to all zoologists, but it is possible that the less well-known Bathynellidæ may have an even greater interest. On account of their small size, these have tended to be overlooked, but no one has deveted more attention to them than has Dr. P. A. Chappuis, of the Speleological Institute at Cluj, in Transylvania. His work, extended over many years, has been carried on through the difficult times of the War, and the accounts of it have recently reached us in a series of papers dealing with subterranean fauna in general. As much of the more interesting results have been published in some of the less readily accessible journals of central and south-eastern Europe, a review of these may be of interest to zoologists.

An account of the history of Bathynella, and the related genus Parabathynella, was given by Chappuis ${ }^{1}$ in 1939, the main points of which may be briefly recapitulated. Bathynellawas discovered by Vedjovsky in 1880, from a well in Prague. His description, published two years later, was based on two specimens one of which was later lost, the other being a poor preparation mounted in Canada balsam. Vedjovsky, at that time, did not attempt to classify this crustacean, regarding it as of uncertain position, but he believed that it was of common occurrence and had previously been overlooked owing to its small size (1.5 mm.). In 1899 Calman $^{2}$, on a re-examination of Nedjovsky's preparation, was able to place it in the Syncarida. It then receded into the background-if not into oblivion-since no one was able to find more specimens until Chappuis, in 1913, rediscovered it in an abandoned well near Basle. Shortly after his discovery the well was filled in and the new source thus lost, but not before Chappuis had collected a number of specimens, three of which he sent to the British Museum (Natural History). These enabled Calman to give a thorough description of Bathynella ${ }^{3}$. Three years later, Chappuis again found Bathynella in the Swiss Jura Mountains, and sent specimens to Delachaux, who described these as a second species which he named after Dr. Chappuis.

Since then, owing to the intensification of interest in the fauna of underground waters, it has been found in many places in Europe, as shown on the chart given by Chappuis ${ }^{1}$. Its discovery in England by Lowndes ${ }^{4}$ was by chance, but is none the less interesting on that account.

The related genus Parabathynella was first described by Chappuis ${ }^{5}$ in 1926, his specimens having been obtained from a stream flowing from the Sveta Voda Cave in Jugoslavia. A second species was described by Sars $^{6}$ in 1929, from the Batu Cave, Kuala Lumpur, and Karaman ${ }^{7}$ extended our knowledge of the European species by finding more mature specimens at Skoplje. These were regarded by Chappuis ${ }^{1}$ as belonging to a distinct species, but there would not appear to be adequate grounds for this view.

It is a characteristic feature of the Bathynellidæ that, up to 1939 , they had always been found in wells, in springs, or in streams in caves; that is to say, they are associated with water of subterranean origin. Because of the isolated nature of the localities where Bathynellidæ had been found, Chappuis ${ }^{8}$ considered the possibility of their having been transported from one body of water to another over the surface. $\mathrm{He}$ concluded that this was most improbable, and it has been generally assumed that they inhabited the water of crevices (Spaltengewässer) which were in general intercommunication, a hypothesis which it is difficult to accept in view of their occurrence at points so far removed from the apparent centre of distribution as in the Pyrenees and in England.

Chappuis's more recent work, however, has shed new light on this problem, and has opened a new field of investigation. Largely as the result of the work of the late Dr. C. B. Wilson ${ }^{2}$, it has been known for some time that the interstitial spaces of sandy beaches are inhabited by a varied and extensive fauna in which copepods are abundant. This fauna is not restricted to the marine environment, but is also to be found around the shores of lakes, and this environment has also received much attention of recent years ${ }^{10}$. Chappuis ${ }^{11}$ has now extended these investigations to yet another type of habitat. $\mathrm{He}$ has found that by digging holes in the sand and rubble within a fow yards of swiftly flowing streams, and by collecting and filtering the water which accumulates in such pools, he has been able to collect a considerable and varied fauna. 